\title{
Retinoblastoma: emerging concepts in genetics, global disease burden, chemotherapy outcomes, and psychological impact
}

\author{
Carol L. Shields $\mathbb{D}^{1}{ }^{\boxplus}$, Zeynep Bas ${ }^{1}$, Andrea Laiton ${ }^{1}$, Ana Maria Velasco Silva ${ }^{1}$, Ahmed Sheikh ${ }^{1}$, Sara E. Lally ${ }^{1}$ and Jerry A. Shields ${ }^{1}$
}

(c) The Author(s), under exclusive licence to The Royal College of Ophthalmologists 2022

In this review we discuss several recent concepts regarding retinoblastoma control and its impact. In a cohort of 482 patients with solitary unilateral retinoblastoma revealed germline mutation in $16 \%$ and the likelihood of germline retinoblastoma was greater for younger children ( $\leq 1$ year versus (vs.) $>1$ year at presentation) with odds ratio (OR) $2.96(p=0.001)$, and greatest for the youngest infants ( $\leq 3$ months vs. $>3-12$ months) (OR 5.52) ( $p=0.002$ ). Retinocytoma/retinoma, a benign variant of retinoblastoma, was studied in 78 tumours and demonstrated transformation into retinoblastoma in $9.2 \%$ by 5 years and $15.3 \%$ by 10 years and 20 years. An international global study on retinoblastoma over 1.5 years revealed 4351 new patients and $85 \%$ from low- and middleincome countries, notably with older age at detection and greater risk for metastasis. Management of retinoblastoma in 964 eyes using intravenous chemotherapy showed 20 -year globe salvage at $96 \%$ in group A, $90 \%$ in group B, $90 \%$ in group C, $68 \%$ in group $D$, and $32 \%$ in group $E$ eyes. The 5-year globe salvage with intra-arterial chemotherapy for 160 eyes (655 infusions) with retinoblastoma showed success in 100\% for group B, 80\% for group C, 78\% for group D, and 55\% for group E. The psychological impact of retinoblastoma on the parents revealed depression (73\%), anxiety (64\%), and/or stress (100\%), and on the patient revealed deficits in quality of life issues. Retinoblastoma is a challenging disease and chemotherapy provides reliable tumour control and globe salvage. Continuing efforts to improve quality of life issues is important.

Eye (2023) 37:815-822; https://doi.org/10.1038/s41433-022-01980-0

\section{INTRODUCTION}

Retinoblastoma is a dangerous malignancy that classically occurs in the eye(s) of children. In high-income countries, including the United States and most of Europe, this malignancy is commonly detected prior to invasion of the optic nerve, choroid, sclera, and orbit and systemic survival is favorable. However, in low and and middle-income nations, particularly in Africa, this malignancy demonstrates evidence of invasive disease, with risks for local and remote metastasis and systemic chemotherapy is necessary for survival [1-6]. The management of retinoblastoma includes enucleation, methods of chemotherapy by various routes of intravenous, intra-arterial, intravitreal, and intracameral infusion, and focal therapies with plaque radiotherapy, cryotherapy, and laser photocoagulation/thermotherapy $[1,7,8]$.

In this review, we will cover recently-published topics related to risk for germline mutation in children presenting with solitary unilateral retinoblastoma, risk for benign retinocytoma/retinoma transformation into active malignant retinoblastoma, retinoblastoma survival outcomes based on global income and the American Joint Committee on Cancer (AJCC) 8th edition, trilateral retinoblastoma screening, long-term globe salvage following intravenous and/or intra-arterial chemotherapy, and the psychologic impact of this disease on the patient and the family.

Germline mutation in unilateral solitary retinoblastoma Previous publications have documented germline mutation in unilateral solitary retinoblastoma at approximately $7-33 \%$ of patients [9-13]. Schüler et al. reviewed 188 patients with solitary unilateral retinoblastoma and found $13 \%$ with genetic testing showing germline mutation [9]. Brichard et al. found similar $11 \%$ of 36 patients with solitary unilateral retinoblastoma showing germline mutation, and with mean age of 22 months at presentation [10]. Nichols et al. found $14 \%$ of 173 patients with sporadic unilateral retinoblastoma showing germline mutation [11]. Gregersen et al. reviewed a database from 1943 to 2013 of solitary unilateral retinoblastoma and found only $7 \%$ with germline mutation [12]. Berry et al. found $18 \%$ of 182 patients with solitary unilateral retinoblastoma without family history of retinoblastoma with germline mutation, several with mosaicism [13]. Others have noted up to $30 \%$ and $33 \%$ of solitary unilateral retinoblastoma with germline mutation $[14,15]$.

Shields et al. recently reviewed a large cohort of 482 patients with solitary unilateral retinoblastoma over nearly 50 years and found $16 \%$ were likely germline mutation based on positive family history, development of new tumours or bilateral disease, and the "gold standard" of genetic testing for germline mutation [16] (Fig. 1). They commented that genetic testing was not universally available so they used the all-inclusive term of "likely germline mutation", based on the above features of family history, tumour multiplicity/bilaterality, as well as genetic testing. They found that likelihood for germline mutation in unilateral solitary retinoblastoma varied depending on age (0-1 year, $>1-2$ years, $>2-3$ years, $>3$ years) with results showing $(29 \%, 17 \%, 8 \%, 9 \%, p=0.001)$. (Table 1) Further analysis into infants ( $0-3$ months, $>3-6$ months,

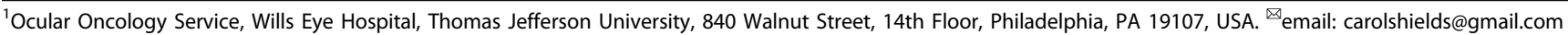




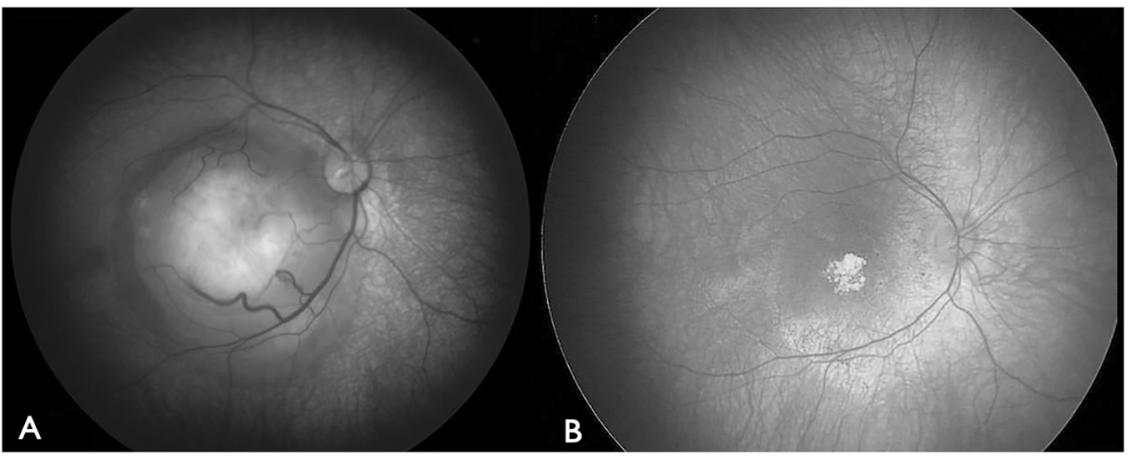

Fig. 1 Unilateral sporadic retinoblastoma in a child. Unilateral sporadic retinoblastoma in a child of 13 months of age with a $17 \%$ risk for germline mutation (See Table 1). A Before and (B) after intra-arterial chemotherapy.

Table 1. Likelihood of germline mutation with solitary retinoblastoma based on patient age group at presentation in 482 cases.

\begin{tabular}{|c|c|c|c|c|c|c|}
\hline Outcomes & Age Bracket & & & & $p$ value & Total \\
\hline \multirow[t]{3}{*}{ Outcomes for all patients of any age } & Age 0-1 year & Age $>1-2$ years & Age $>2-3$ years & Age $>3$ years & & Overall \\
\hline & $(n=132)$ & $(n=122)$ & $(n=97)$ & $(n=131)$ & & $(N=482)$ \\
\hline & {$[n(\%)]$} & {$[n(\%)]$} & {$[n(\%)]$} & {$[n(\%)]$} & & {$[N(\%)]$} \\
\hline Likely germline disease* & $n=126$ & $n=117$ & $n=93$ & $n=126$ & & $n=462$ \\
\hline No & $89(71)$ & $100(85)$ & $86(92)$ & $115(91)$ & 0.001 & $390(84)$ \\
\hline Yes & $37(29)$ & $17(17)$ & $7(8)$ & $11(9)$ & & $72(16)$ \\
\hline & $(n=23)$ & $(n=27)$ & $(n=42)$ & $(n=40)$ & & $(N=132)$ \\
\hline & {$[n(\%)]$} & {$[n(\%)]$} & {$[n(\%)]$} & {$[n(\%)]$} & & {$[N(\%)]$} \\
\hline Likely germline disease* & $n=23$ & $n=25$ & $n=40$ & $n=37$ & & $n=126$ \\
\hline No & 9 (39) & $20(80)$ & 31 (76) & $29(78)$ & 0.009 & 89 (71) \\
\hline Yes & $14(61)$ & $5(20)$ & $10(24)$ & $8(22)$ & & $37(29)$ \\
\hline
\end{tabular}

Bold $p$ values indicate statistical significance.

* Likely germline disease defined by positive family history of retinoblastoma, development of bilateral tumours or new tumours, and/or germline positive genetic testing.

Information adapted from Shields CL, Dockery PW, Ruben M, et al. Likelihood of germline mutation with solitary unilateral retinoblastoma based on patient age at presentation. Analysis of 482 consecutive patients. J Pediatr Ophthalmol Strabism. 2021. Jun 1;1-10. https://doi.org/10.3928/01913913-20210414-02. Online ahead of print [16].

$>6-9$ months, >9-12 months) with solitary unilateral retinoblastoma revealed results showing $(61 \%, 20 \%, 24 \%, 22 \%, p=0.009)$.

These findings are relevant to decisions from ocular oncologists regarding patient management based on the presence or absence of germline disease. For patients with germline mutation, an attempt to conserve both eyes as well as protect from pinealoblastoma and second cancers is considered.

Currently, the use of next-generation sequencing (NGS) has advanced our understanding of retinoblastoma. Children with unilateral retinoblastoma could potentially be served with NGS of the cell free DNA (cfDNA) in the blood and aqueous humor to confirm the diagnosis of retinoblastoma and provide information on subtypes of retinoblastoma that might be at risk for recurrence following chemotherapy and impact treatment planning [17]. This form of "liquid biopsy" can be used for confirmation of diagnosis as well as monitoring tumour response during therapy.

\section{Conditional risks for germline mutation in unilateral solitary retinoblastoma}

Shields et al. further explored the 482 patients with solitary unilateral retinoblastoma specifically for new tumours (55 new tumours in 20 patients) using non-conditional and conditional analysis [18]. Comparison (new tumour vs. no new tumour development) revealed those with new tumour were younger at presentation (10 vs. 36 months, $p<0.001$ ), with family history of retinoblastoma (35\% vs. $3 \%, p<0.001$ ), less advanced tumour $(p=0.012)$, and greater macula location of first tumour $(50 \%$ vs. $15 \%, p=0.003$ ). Conditional risk for new tumours (at age $6,9,12$, 18,24 months) dynamically declined with increasing age (Table 2). Of those with new tumours, those that occurred $\leq 1$ year from presentation were located more posteriorly whereas those that occurred $>1$ year from presentation were more likely to occur near the ora serrata. Importantly, patients $\leq 24$ months at presentation demonstrated all new tumoursby 24 months of age, whereas older patients ( $>24$ months at presentation) showed new tumoursup to 56 months of age.

Retinocytoma/retinoma: risk for growth into retinoblastoma Retinocytoma/retinoma refer to a benign variant of retinoblastoma, representing only $3 \%$ of all cases [19-24]. The older literature focused mostly on terminology and clinical features of this unique tumour [19-23]. In 2000, Singh et al. reviewed 24 tumoursin 17 patients from our department and documented only 1 case (4\%) with evidence of growth into retinoblastoma over median follow up of 4 years [24]. Dimaris et al. subsequently published on genomic instability in retinocytoma/retinoma at risk for transformation into retinoblastoma [25]. They showed that quiescent retinocytoma/retinoma demonstrated loss of both RB1 tumour suppressor gene alleles and low level genomic instability and high expression of senescent proteins that lead to stability in 


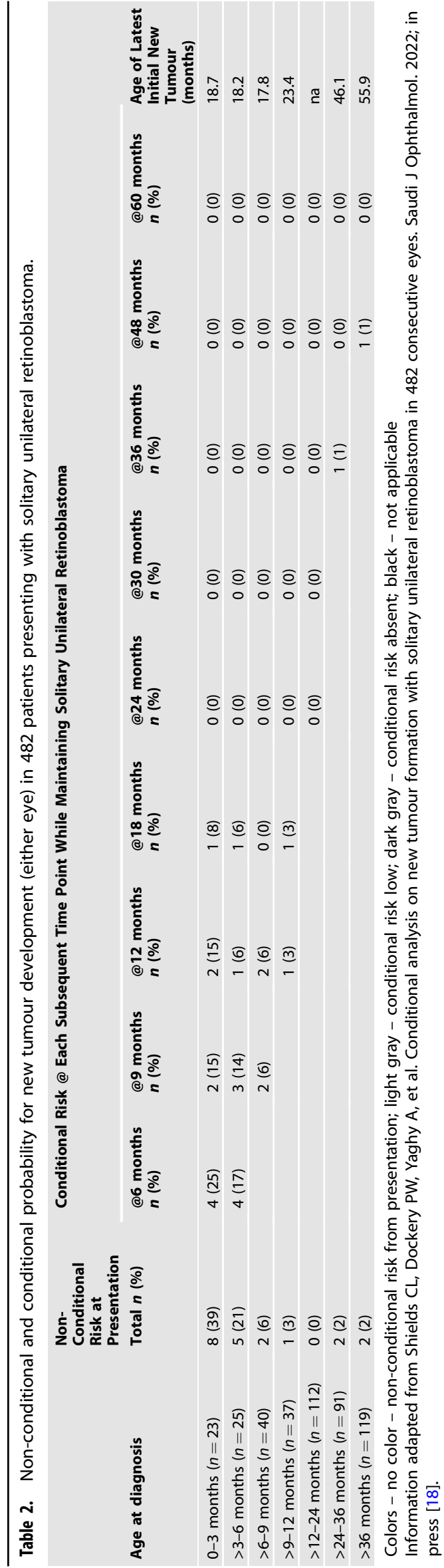

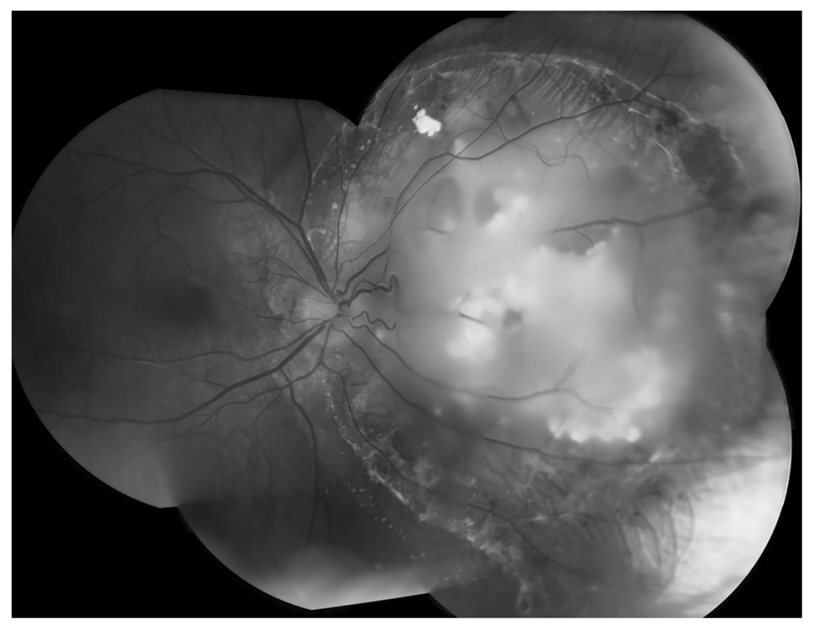

Fig. 2 Retinocytoma in a child. Spontaneously regressed retinoblastoma (retinocytoma) in a pre-teen child with low risk for transformation into retinoblastoma (See Table 3).

most cases, but instability could further lead to transformation into retinoblastoma.

Shields et al. looked into long-term clinical evidence of transformation of retinocytoma/retinoma into retinoblastoma in a fairly large cohort of these 78 benign tumours in 62 patients [26] (Fig. 2). At presentation with retinocytoma/retinoma, the median patient age was 5 years, older than most children with retinoblastoma. The retinocytoma/retinoma demonstrated median basal diameter of $6.0 \mathrm{~mm}$ and thickness of $2.3 \mathrm{~mm}$ without surrounding retinal pigment epithelial (RPE) alterations (31\%) or with RPE alterations (69\%). A comparative analysis based on age at presentation ( $<4$ vs. $\geq 4$ years) revealed younger patients being more likely Hispanic ( $19 \%$ vs. $2 \%, p=0.04$ ) and with leukocoria ( $24 \%$ vs. $0 \%, p=0.003)$. A comparative analysis based on tumour focality (unifocal vs. multifocal) revealed unifocal tumour with lack of symptoms ( $62 \%$ vs. $25 \%, p=0.03)$, and greater median basal diameter ( 6.0 vs. $3.3, p=0.003$ ) and thickness ( 2.5 vs. $1.5 \mathrm{~mm}, p=$ 0.006) [26]. By Kaplan-Meier analysis, retinocytoma/retinoma transformation into retinoblastoma was found in $2.7 \%$ by 2 years, $9.2 \%$ by 5 years, $15.3 \%$ by 10 years and 20 years [26] (Table 3 ). The only factor predictive of transformation by multivariate analysis was increasing thickness $(p=0.003)$ with hazard ratio of 2.83 per $1 \mathrm{~mm}$ increase in thickness.

\section{Retinoblastoma: outcomes based on global income level}

A 2009 survey of the world incidence of retinoblastoma by Kivela revealed the disease heavily concentrated (\#/year) in Asia (4027 cases), Africa (1792 cases), and Latin America (622 cases) compared with Europe (414 cases), North America (258 cases), Japan (59 cases), and Oceania (21 cases) [5]. Mortality rate was greatest in Africa (70\%), Asia (39\%), and Latin America (20\%) and least in Europe (5\%), Japan (3\%), and North America (3\%) [5].

In 2020, The Global Retinoblastoma Group, led by Fabian et al. published a report on global retinoblastoma features by national income level and found that of 4351 new patients from 153 countries studied from June 2017 to December 2018, most (85\%) were from low and middle-income countries [6]. The most common features included leukocoria (63\%), strabismus (10\%), and proptosis $(7 \%)$. Those patients from high-income countries were diagnosed at median age of 14 months, $2 \%$ with extraocular tumour, and only $<1 \%$ incidence of remote metastasis, compared to low-income countries with median age at presentation of 31 months, 49\% with extraocular tumour, and 19\% with remote metastasis [6]. They suggested that these concerning findings need to be addressed at a national or international level. 


\section{Retinoblastoma: global retinoblastoma during Covid-19}

In 2021, The Global Retinoblastoma Group, led by Fabian et al. published a letter to the editor on retinoblastoma management during the Covid-19 pandemic and noted that $\sim 42 \%$ of the 194 participating centers reported restrictions for families to reach a retinoblastoma center and $40 \%$ also noted that management disruption occurred due to personnel or equipment problems [27]. Fortunately, most centers were able to continue intravenous chemotherapy (94\%) and enucleation (90\%), but intra-arterial chemotherapy was unavailable at $62 \%$ of centers.

\section{Retinoblastoma: outcomes based on AJCC 8th edition}

There are several classification systems for retinoblastoma including the International Classification of Retinoblastoma (ICRB) and the American Joint Committee on Cancer (AJCC). The AJCC is currently in the 8th edition and Tomar et al. studied retinoblastoma based on the AJCC 8th edition using collaborative data in 2085 patients and found the 5-year Kaplan-Meier rate of survival decreased with increasing tumour category, revealing CT1a (100\%), cT1b (98\%), cT2a (98\%), cT2b (96\%), cT3 (89\%), and cT4

Table 3. Kaplan-Meier estimates of transformation of retinocytoma/ retinoma to retinoblastoma in 61 tumours of 48 patients.

\begin{tabular}{|c|c|c|}
\hline Year & $\begin{array}{l}\text { Kaplan-Meier estimates } \% \\
\text { per patient }\end{array}$ & $\begin{array}{l}\text { Kaplan-Meier estimates \% } \\
\text { per tumour }\end{array}$ \\
\hline 1 & $0 \%$ & $0 \%$ \\
\hline 2 & $2.7 \%$ & $2.1 \%$ \\
\hline 3 & $9.2 \%$ & $6.9 \%$ \\
\hline 4 & $9.2 \%$ & $6.9 \%$ \\
\hline 5 & $9.2 \%$ & $6.9 \%$ \\
\hline 6 & $9.2 \%$ & $6.9 \%$ \\
\hline 7 & $15.3 \%$ & $10.8 \%$ \\
\hline 8 & $15.3 \%$ & $10.8 \%$ \\
\hline 9 & $15.3 \%$ & $10.8 \%$ \\
\hline 10 & $15.3 \%$ & $10.8 \%$ \\
\hline 15 & $15.3 \%$ & $10.8 \%$ \\
\hline 20 & $15.3 \%$ & $10.8 \%$ \\
\hline
\end{tabular}

Information adapted from Shields $\mathrm{CL}$, Srinivasan $\mathrm{A}$, Alvarez JAL, et al Retinocytoma/retinoma: Comparative analysis of clinical features in 78 tumours and rate of transformation into retinoblastoma over 20 years. J AAPOS. 2021 Jun;25(3):147.e1-147.e8. https://doi.org/10.1016/j.jaapos. 2020.11.024. Epub 2021 May 26.PMID: 34051357 [26].
(45\%) [28]. Outcomes related to the ICRB are listed below under headings "Retinoblastoma: Long-term (20-year) outcomes following intravenous chemotherapy" and "Retinoblastoma: Long-term (20-year) outcomes following intravenous chemotherapy".

\section{Retinoblastoma: screening for trilateral retinoblastoma}

Trilateral retinoblastoma is a condition whereby a child with bilateral retinoblastoma develops germline-mutation-related pinealoblastoma or other intracranial neoplasm and this combination carries high risk for death $[29,30]$. There is some evidence that systemic chemotherapy might reduce the incidence of pinealoblastoma in hereditary retinoblastoma [31]. Kivela provided a meta-analysis on the clinical features and outcomes of trilateral retinoblastoma in 106 cases [30]. He noted the median age at diagnosis of the brain neoplasm was 5 months and typically affected second or third generation families with retinoblastoma. Importantly they realized that routine neuroimaging with magnetic resonance imaging (MRI) could detect smaller tumours, associated with better 5-year survival.

De Jong et al. revisited screening for trilateral retinoblastoma in 138 cases and found $84 \%$ were symptomatic and $16 \%$ asymptomatic [32]. In those asymptomatic cases, 95\% were diagnosed before age 40 months (Fig. 3). Overall, age at diagnosis of the pineal tumour did not correlate with age at diagnosis of the retinoblastoma [32]. They stated that MRI on a 6-month basis in cases of heritable retinoblastoma up until 3 years of age can detect pineal tumour, but it would take 311 MRI scans to find 1 asymptomatic pineal tumour and $776 \mathrm{MRI}$ scans to save one life.

\section{Retinoblastoma: long-term (20-year) outcomes following intravenous chemotherapy}

In the early 1990s, Kingston et al. noted that a certain systemic chemotherapy protocol, initially designed for neuroblastoma, was effective for retinoblastoma. They and others published initial observations on the efficacy of this approach [33-37]. In 2006, Shields et al. published results of intravenous chemotherapy (vincristine, etoposide, carboplatin) in 249 consecutive cases of retinoblastoma and found tumour control with globe salvage and (avoiding external beam radiotherapy) in 100\% of group A, $93 \%$ of group B, $90 \%$ of group C, and $47 \%$ of group D eyes [38]. All group $\mathrm{E}$ eyes were enucleated.

In 2020, Shields et al. published on a larger cohort of 964 eyes in 554 patients treated with similar intravenous chemotherapy with Kaplan-Meier analysis demonstrating globe salvage (avoiding external beam radiotherapy) at 3 years in $96 \%$ of group $A, 91 \%$ of group $B, 91 \%$ of group $C, 71 \%$ of group $D$, and $32 \%$ of group $E$ eyes [39] (Figs. 4 and 5). This control and globe salvage was

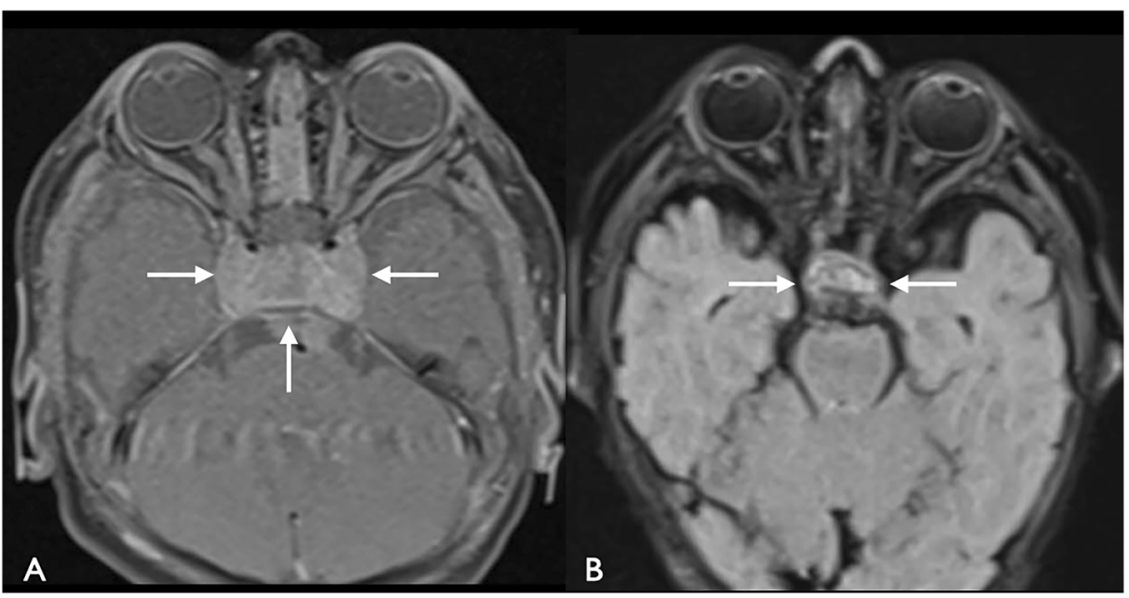

Fig. 3 Trilateral retinoblastoma. Two-year old child with trilateral retinoblastoma and brain tumour (arrows) (A) before and (B) 2 months after high dose systemic chemotherapy. 


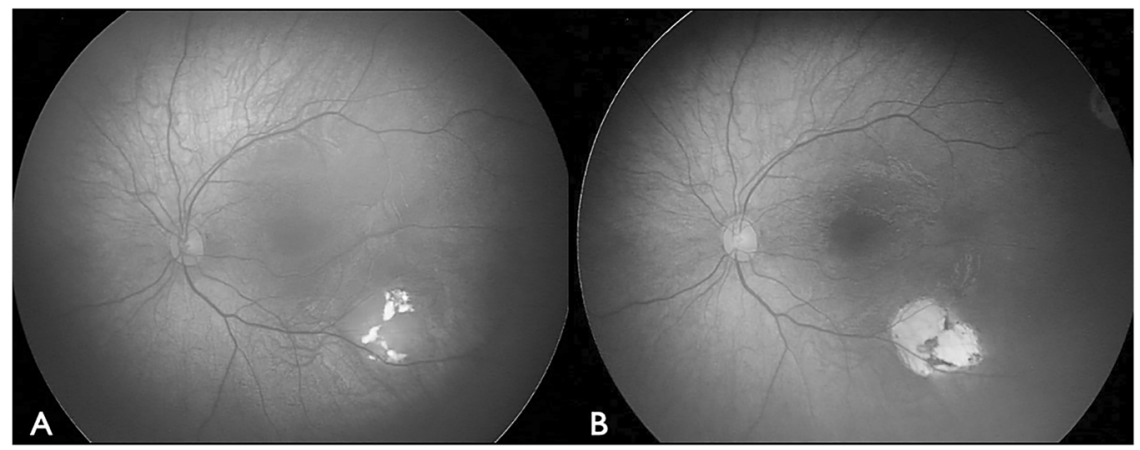

Fig. 4 Intravenous chemotherapy for retinoblastoma. Intravenous chemotherapy plus transpupillary thermotherapy for Group B retinoblastoma showing control (A) before and (B) after treatment.

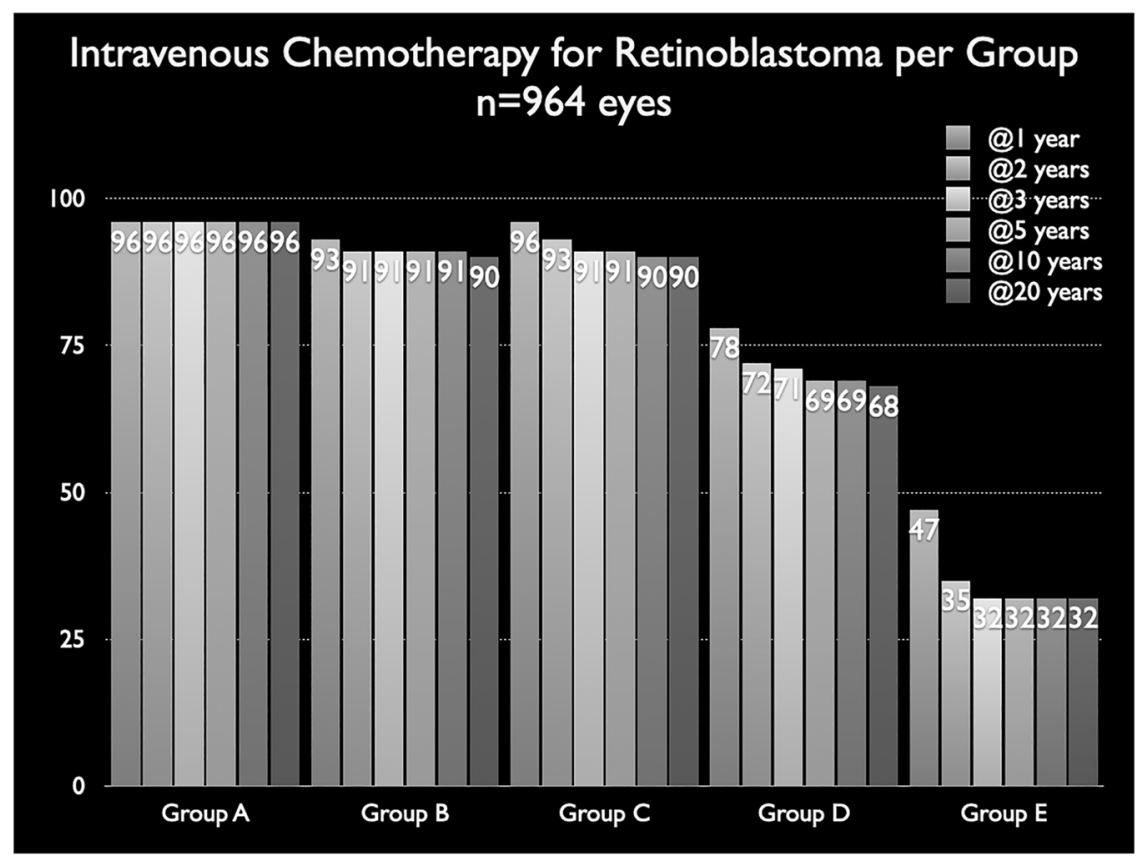

Fig. 5 Intravenous chemotherapy for retinoblastoma per group in 964 eyes. Globe salvage at 1, 2, 3, 5, 10, and 20 years by Kaplan-Meier analysis. (Data adapted from reference [39], Shields CL, Bas Z, Tadepalli S, et al. Long-Term (20-year) real-world outcomes of intravenous chemotherapy (chemoreduction) for retinoblastoma in 964 eyes of 554 patients at a single Center. Br J Ophthalmol. 2020;104:1548-55.).

maintained at 20 years follow up. In order to preserve the eye(s), additional intra-arterial chemotherapy (IAC) or plaque radiotherapy was employed by year 2 in $5 \%$ of group $A, 26 \%$ of group $B, 28 \%$ of group C, $27 \%$ of group D, and $19 \%$ of group $E$ eyes, with little further need beyond 2 years up to 20 years. Bas et al. studied outcomes in this cohort based on patient age and noted that younger patients demonstrated more lasting control than older patients [40]. As written in an editorial, the excellent control offered by intravenous chemotherapy has revolutionized retinoblastoma care [41].

\section{Retinoblastoma: long-term (14-year) outcomes following intra-arterial chemotherapy}

Intra-arterial chemotherapy is a targeted chemotherapy directly to the eye for retinoblastoma treatment. This modality can be used as primary or secondary treatment and can be applied to one or both eyes [42-47]. According to the International Classification of Retinoblastoma (ICRB), globe salvage as primary therapy has been highly successful for groups $A, B$, and $C$ retinoblastoma, and moderately successful for groups $D$ and $E$, depending on tumour extent [42-50]. A collaborative report on IAC for retinoblastoma from six international retinoblastoma centers using 4396 chemotherapy infusions in 1139 patients over a 10-year period found only 3 metastatic deaths $(<1 \%)$ [49]. It is encouraged that this technique be performed only at experienced centers [50].

Shields et al. reported 14-year outcomes following primary or secondary IAC for retinoblastoma in 341 eyes treated with 1292 infusions [47]. Overall, Kaplan-Meier 5-year estimates of globe salvage was $74 \%$. Of those treated with primary IAC ( $n=160$ eyes, 655 infusions), 5-year globe salvage was 76\%, including 100\% for group B, $80 \%$ for group C, $78 \%$ for group D, and $55 \%$ for group $E$. (Figs. 6, 7 and 8) Of those treated with secondary IAC $(n=207$ eyes, 859 infusions), 5-year globe salvage was $71 \%$. Complications (per catheterization) were minimal in this experienced team, including retinal ischemia (1\%), choroidal ischemia (1\%), neovascularization disc, retina, iris, or glaucoma ( $1 \%$ each), and systemic ischemia $(<1 \%)$. There was minimal difference in outcomes when evaluating by age, race, and sex.

\section{Retinoblastoma: outcomes following intravitreal chemotherapy}

In the past, vitreous seeding from retinoblastoma was a particular concern as only radiotherapy or enucleation was available for treatment and many eyes were enucleated. In 2012, Munier et al. 


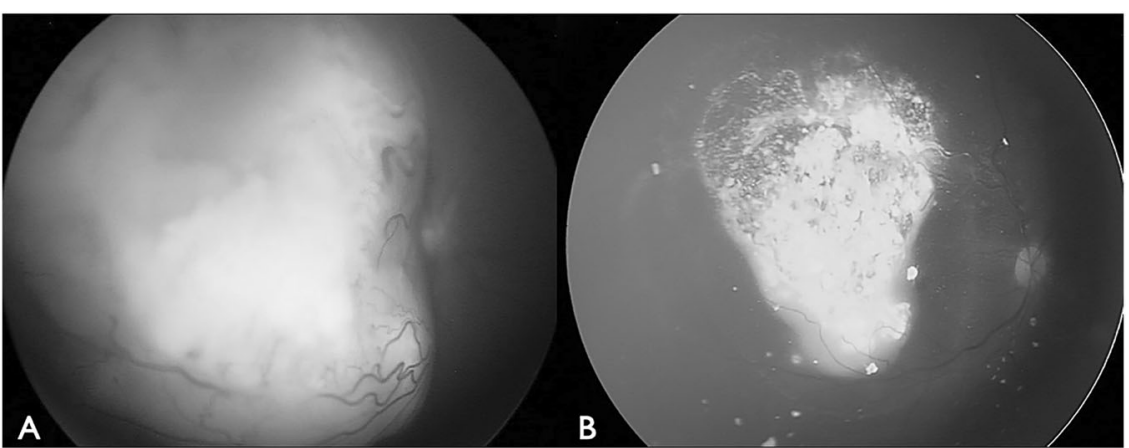

Fig. 6 Intra-arterial chemotherapy for large retinoblastoma. Intra-arterial chemotherapy for Group D retinoblastoma with extensive subretinal seeding, showing control (A) before and (B) after treatment.

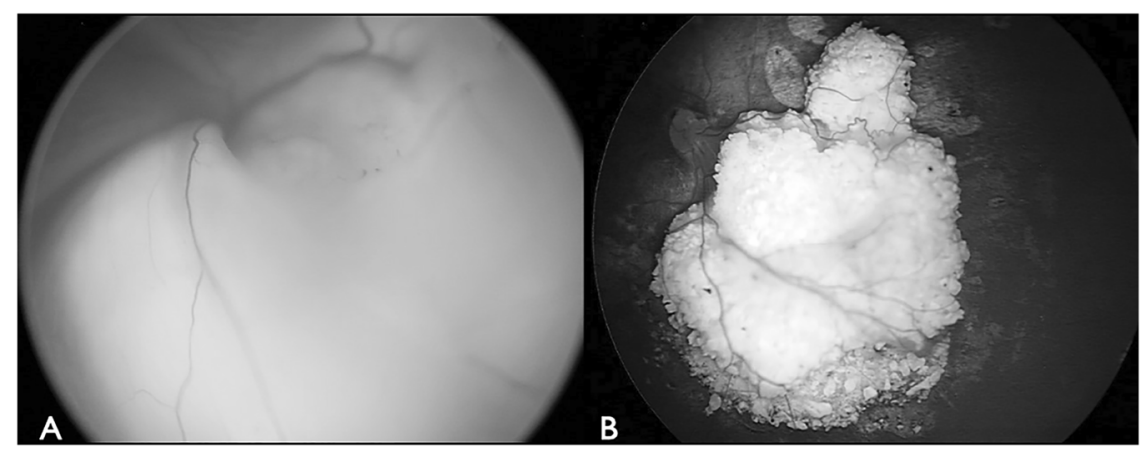

Fig. 7 Intra-arterial chemotherapy for advanced retinoblastoma. Intra-arterial chemotherapy for Group E retinoblastoma with extensive subretinal seeding for all clock hours and no view of the optic disc, showing control (A) before and (B) after treatment.

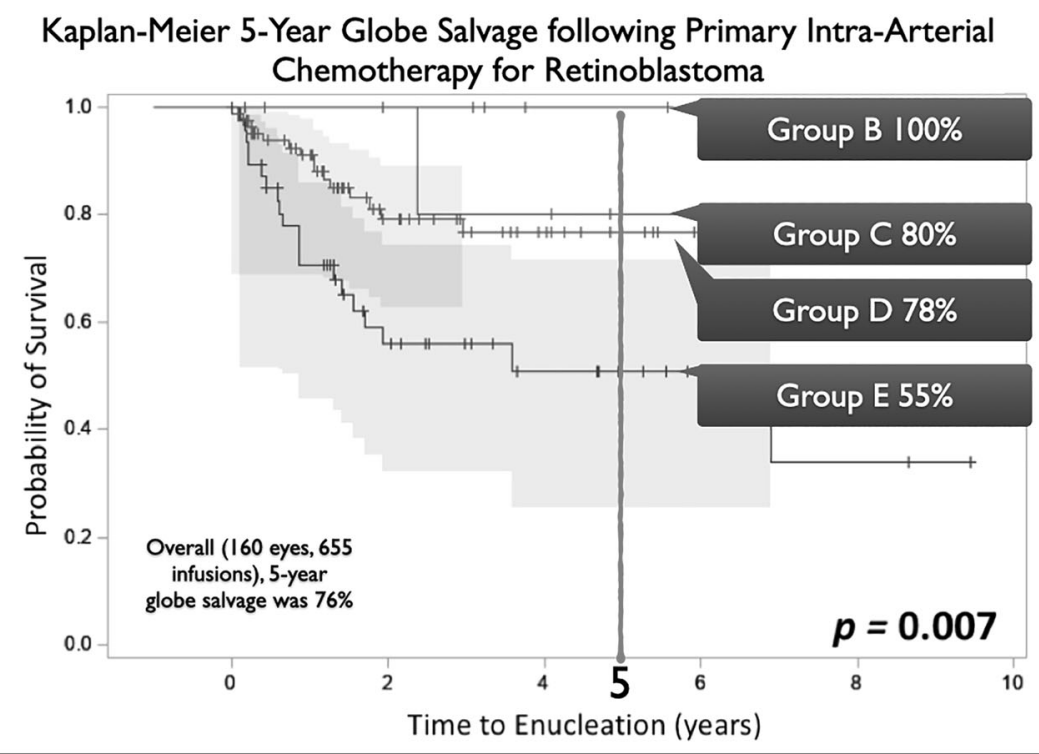

\section{- Group B — Group C — Group D - Group E}

Fig. 8 Intra-arterial chemotherapy for retinoblastoma per group in $\mathbf{1 6 0}$ eyes (655 infusions). Globe salvage at 5 years by Kaplan-Meier analysis. (Data adapted from reference [47], Shields CL, Dockery PW, Yaghy A, et al. Intra-arterial chemotherapy for retinoblastoma in 341 consecutive eyes (1292 infusions): Comparative analysis of outcomes based on patient age, race, and sex. J AAPOS. 2021. [In press]).

[51] and Ghassemi and Shields [52] published the use of injection of chemotherapy into the vitreous cavity for management of retinoblastoma seeding with favorable results. Later, in 2016, Shields et al. reviewed 192 chemotherapy injections for retinoblastoma vitreous seeding and found $100 \%$ tumour control [53]. In 2017, Francis et al. collaborated with 10 international centers and found complications of extraocular tumour seeding to be exquisitely rare, if proper safety precautions were employed [54].

Psychological adaptation to retinoblastoma and vision loss Retinoblastoma not only affects the patient, but it can impact the entire family. A study by Collins et al. provided a thesis evaluation 
of 138 parents of children with retinoblastoma using standardized self-reported psychological assessment indexes and found that most parents display depression (73\%), anxiety (64\%), and/or stress (100\%) [55]. Severe parental depression is more commonly seen with those children who display multifocal retinoblastoma and those with less education and previous history of depression. These authors emphasized that the psychological status of the family is an important consideration when managing a family with retinoblastoma.

Parravano et al. provided a meta-analysis of 27 studies of 6992 patients with acquired visual acuity impairment in individuals over 18 years of age [56]. In their cohort, the mean age at evaluation was 76 years and results showed depression was common in patients, ranging from a prevalence of $24-34 \%$ in clinic-based and rehabilitation-based services [56]. They advised that ophthalmologists should recognize this common problem and address it with each patient and their health care professional.

Dhingra et al. reviewed health-related quality of life (HRQoL) in retinoblastoma survivors in India, studying physical, emotional, social, and school dimensions [57]. Compared to healthy siblings, they found affected survivors with lower HRQoL in all domains $(p<0.01)$, especially the physical aspect.

\section{SUMMARY}

What is known about this topic

- In a published cohort of 482 patients with solitary unilateral retinoblastoma, germline mutation was found in $16 \%$ patients and the likelihood of germline retinoblastoma was greater for younger children ( $\leq 1$ year versus (vs.) $>1$ year at presentation) $(p=0.001)$ and greatest for youngest infants ( $\leq 3$ months vs. $>3-12$ months) $(p=0.002)$.

- An international global study on retinoblastoma during 2017 revealed 4351 new patients and 85\% from low- and middle-income countries. They noted that low- and middleincome countries found patients with older age at detection and greater risk for metastasis, compared to high-income countries.

- Retinocytoma/retinoma is a benign and quite rare variant of retinoblastoma, and a study of 78 tumours demonstrated ultimate transformation into active retinoblastoma in $9.2 \%$ by 5 years and $15.3 \%$ by 10 years and 20 years.

\section{What this study adds}

- Management of retinoblastoma with systemic intravenous chemotherapy in 964 eyes revealed lasting 20-year globe salvage at $96 \%$ in group A, $90 \%$ in group B, $90 \%$ in group C, $68 \%$ in group $D$, and $32 \%$ in group $E$ eyes.

- Management of retinoblastoma with intra-arterial chemotherapy in 160 eyes (655 infusions) revealed 5-year globe salvage was $100 \%$ for group B, $80 \%$ for group C, $78 \%$ for group D, and $55 \%$ for group $\mathrm{E}$.

- The psychological impact of retinoblastoma on the parents revealed depression (73\%), anxiety (64\%), and/or stress (100\%), and on the patient revealed deficits in quality-of-life issues.

- Retinoblastoma is a challenging disease and chemotherapy provides reliable tumour control and globe salvage. Continuing efforts to improve the psychology and quality of life is important.

\section{REFERENCES}

1. Shields CL, Lally SE, Leahey AM, Jabbour PM, Caywood EH, Schwendeman R, et al. Targeted retinoblastoma management: when to use intravenous, intra-arterial, periocular, and intravitreal chemotherapy. Curr Opin Ophthalmol. 2014; 25:374-85.

2. Ancona-Lezama D, Dalvin LA, Shields CL. Modern treatment of retinoblastoma: a 2020 review. Ind J Ophthalmol. 2020;68:2356-65.

3. Honavar SG, Singh AD, Shields CL, Meadows AM, Demirci H, Cater J, et al. Postenucleation adjuvant therapy in high-risk retinoblastoma. Arch Ophthalmol. 2002;120:923-31.

4. Kaliki S, Shields CL, Shah SU, Eagle RC Jr, Shields JA, Leahey A. Postenucleation adjuvant chemotherapy with vincristine, etoposide, and carboplatin for the treatment of high-risk retinoblastoma. Arch Ophthalmol. 2011;129:1422-7.

5. Kivela $T$. The epidemiological challenge of the most frequent eye cancer: retinoblastoma, an issue of birth and death. Br J Opthalmol. 2009;93:1129-31.

6. Global Retinoblastoma Study Group. Global retinoblastoma presentation and analysis by national income level. JAMA Oncol. 2020;6:685-95.

7. Shields JA, Shields CL. Intraocular Tumors. An Atlas and Textbook. 3rd edition. Philadelphia, Lippincott Wolters Kluwers, 2016:335-72.

8. Ramasubramanian A, Shields $C L$, editors. Retinoblastoma. New Delhi, India: Jaypee Brothers Medical Publishers; 2012:37-78.

9. Schüler A, Weber $S$, Neuhäuser $M$, Jurklies $C$, Lehnert $T$, Heimann $H$, et al. Age at diagnosis of isolated unilateral retinoblastoma does not distinguish patients with and without a constitutional RB1 gene mutation but is influenced by a parent-oforigin effect. Eur J Cancer. 2005;41:735-40.

10. Brichard B, Heusterspreute M, De Potter P, Chantrain C, Vermylen C, Sibille C, et al. Unilateral retinoblastoma, lack of familial history and older age does not exclude germline RB1 gene mutation. Eur J Cancer. 2006;42:65-72.

11. Nichols $\mathrm{KE}$, Walther $\mathrm{S}$, Chao E, Shields $\mathrm{CL}$, Ganguly A. Recent advances in retinoblastoma genetic research. Curr Opin Ophthalmol. 2009;20:351-5.

12. Gregersen PA, Urbak SF, Funding M, Overgaard J, Jensen UB, Alsner J. Danish retinoblastoma patients 1943-2013 - genetic testing and clinical implications. Acta Oncol. 2016;55:412-7.

13. Berry JL, Lewis L, Zolfaghari E, Green S, Le BHA, Lee TC, et al. Lack of correlation between age at diagnosis and RB1 mutations for unilateral retinoblastoma: The importance of genetic testing. Ophthalmic Genet. 2018;39:407-9.

14. Yousef YA, Tbakhi A, Al-Hussaini M, AlNawaiseh I, Saab A, Afifi A, et al. Mutational analysis of the RB1 gene and the inheritance patterns of retinoblastoma in Jordan. Fam Cancer. 2018;17:261-8.

15. Rojanaporn D, Boontawon T, Chareonsirisuthigul T, Thanapanpanich O, Atteseth $T$, Saengwimol D, et al. Spectrum of germline RB1 mutations and clinical manifestations in retinoblastoma patients from Thailand. Mol Vis. 2018;24:778-88.

16. Shields CL, Dockery PW, Ruben M, Yaghy A, Sunday MA, Levin HJ, et al. Likelihood of germline mutation with solitary unilateral retinoblastoma based on patient age at presentation. Analysis of 482 consecutive patients. J Pediatr Ophthalmol Strabism. 2021;1:1-10. https://doi.org/10.3928/01913913-20210414-02. Jun. Online ahead of print. PMID: 34180289.

17. Gudiseva HV, Berry JL, Polski A, Tummina SJ, O'Brien JM. Next-generation technologies and strategies for the management of retinoblastoma. Genes. 2019;10:1032. https://doi.org/10.3390/genes10121032.

18. Shields CL, Dockery PW, Yaghy A, Ruben M, Sunday MA, Calotti M, et al. Conditional analysis on new tumor formation with solitary unilateral retinoblastoma in 482 consecutive eyes. Saudi J Ophthalmol. 2022; in press.

19. Abramson DH. Retinoma, retinocytoma, and the retinoblastoma gene. Arch Ophthalmol. 1983;101:1517-8.

20. Gallie BA, Ellsworth RM, Abramson DH, Phillips RA. Retinoma: Spontaneous regression of retinoblastoma or benign manifestation of the mutation? $\mathrm{Br} J$ Cancer. 1982;45:513-21.

21. Margo $\mathrm{CH}$, Hidayat A, Kopelman J, Zimmerman LE. Retinocytoma: a benign variant of retinoblastoma. Arch Ophthalmol. 1983;101:1519-31.

22. Gallie BA, Phillips RA, Ellsworth RM, Abramson DH. Significance of retinoma and phthisis bulbi for retinoblastoma. Ophthalmology. 1982;89:1393-9.

23. Balmer A, Munier F, Gailloud C. Retinoma: case studies. Ophthalmic Pediatr Genet. 1991;12:131-7.

24. Singh $A D$, Santos $M C$, Shields $C L$, Shields $J A$, Eagle $R C$. Observations on 17 patients with retinocytoma. Arch Ophthalmol. 2000;118:199-205.

25. Dimaris H, Khetan V, Halliday W, Orlic M, Prigoda NL, Piovesan B, et al. Loss of RB1 induces non-proliferative retinocytoma: Increasing genomic instability correlates with progression to retinoblastoma. Hum Mol Genet. 2008;17:1363-7.

26. Shields CL, Srinivasan A, Alvarez JAL, Shields JA. Retinocytoma/retinoma: comparative analysis of clinical features in 78 tumors and rate of transformation into retinoblastoma over 20 years. J J Aapos. 2021;25:147.e1-147.e8. https://doi.org/ 10.1016/j.jaapos.2020.11.024. Jun. Epub 2021 May 26. PMID: 34051357.

27. Fabian ID, Stacey AW, Bowman R, Khetan V, Blum S, Keren-Froim N, et al. on behalf of the Global Retinoblastoma Study Group. Retinoblastoma management during the COVID-19 pandemic: a report by the Global Retinoblastoma Study Group including 194 centers from 94 countries. Pediatr Blood Cancer. 2021;68: e28584. 
28. Tomar AS, Finger PT, Gallie B, Kivelä $\Pi$, Mallipatna A, Zhang $C$, et al. For the American Joint Committee on Cancer Ophthalmic Oncology Task Force. A multicenter, international collaborative study for American Joint Committee on Cancer staging of retinoblastoma. Ophthalmology. 2020;127:1719-32.

29. De Potter $P$, Shields $C L$, Shields JA. Clinical variations of trilateral retinoblastoma. A report of 13 cases. J Pediatr Ophthalmol Strabism. 1994;31:26-31.

30. Kivela T. Trilateral retinoblastoma: a meta-analysis of hereditary retinoblastoma associated with primary ectopic intracranial retinoblastoma. J Clin Oncol. 1999;17:1829-37.

31. Shields CL, Meadows AT, Shields JA, Carvalho C, Smith A. Chemoreduction for retinoblastoma may prevent intracranial neuroblastic malignancy (trilateral retinoblastoma). Arch Ophthalmol. 2001;119:1269-72.

32. De Jong MC, Kors WA, Moll AC, de Graaf $P$, Castelijns JA, Jansen RW, et al. Screening for pineal trilateral retinoblastoma revisited: a meta-analysis. Ophthalmology. 2020;127:601-7.

33. Kingston JE, Hungerford $\mathrm{JL}$, Madreperla SA, Plowman PN. Results of combined chemotherapy and radiotherapy for advanced intraocular retinoblastoma. Arch Ophthalmol. 1996;114:1339-43.

34. Gallie BL, Budning A, DeBoer G, Thiessen JJ, Koren G, Verjee Z, et al. Chemotherapy with focal therapy can cure intraocular retinoblastoma without radiotherapy. Arch Ophthalmol. 1996;114:1321-8.

35. Murphree AL, Villablanca JG, Deegan WF III, Sato JK, Malogolowkin M, Fisher A, et al. Chemotherapy plus local treatment in the management of intraocular retinoblastoma. Arch Ophthalmol. 1996;114:1348-56.

36. Shields CL, De Potter P, Himelstein BP, Shields JA, Meadows AT, Maris J. Chemoreduction in the initial management of intraocular retinoblastoma. Arch Ophthalmol. 1996;114:1330-8.

37. Ferris FL III, Chew EY. A new era for the treatment of retinoblastoma. Arch Ophthalmol. 1996;114:1412.

38. Shields CL, Mashayekhi A, Au AK, Czyz C, Leahey A, Meadows AT, et al. The International Classification of Retinoblastoma predicts chemoreduction success. Ophthalmology. 2006;113:2276-80.

39. Shields CL, Bas Z, Tadepalli S, Dalvin LA, Rao R, Schwendeman R, et al. Long-Term (20-year) real-world outcomes of intravenous chemotherapy (chemoreduction) for retinoblastoma in 964 eyes of 554 patients at a single centre. $\mathrm{Br} \mathrm{J} \mathrm{Ophthalmol.}$ 2020;104:1548-55.

40. Bas Z, Dalvin LA, Tadepalli S, Rao R, Shah A, Leahey AM, et al. Outcomes of intravenous chemotherapy (chemoreduction) for retinoblastoma based on patient age in 964 eyes of 554 cases. Asia Pac J Ophthalmol. 2021;10:373-80.

41. Shields CL, Shields JA. Here comes the sun for retinoblastoma. Asia Pac J Ophthalmol. 2021;10:341-2.

42. Shields $\mathrm{CL}$, Shields JA. Intra-arterial chemotherapy for retinoblastoma: The beginning of a long journey. Clin Exp Ophthalmol. 2010;38:638-43.

43. Suzuki S, Yamane T, Mohri M, Kaneko A. Selective ophthalmic arterial injection therapy for intraocular retinoblastoma: The long-term prognosis. Ophthalmology. 2011;118:2081-7.

44. Manjandavida FP, Honavar SG, Shields CL, Shields JA. Retinoblastoma: Recent update and management frontiers. Asia Pac J Ophthalmol. 2013;2:351-3.

45. Shields CL, Manjandavida FP, Lally SE, Pieretti G, Arepalli SA, Caywood EH, et al. Intra-arterial chemotherapy for retinoblastoma in 70 eyes: Outcomes based on the international classification of retinoblastoma. Ophthalmology. 2014;121:1453-60.

46. Manjandavida FP, Stathopoulos C, Zhang J, Honavar SG, Shields CL. Intra-arterial chemotherapy in retinoblastoma - A paradigm change. Indian J Ophthalmol. 2019;67:740-54.

47. Shields CL, Dockery PW, Yaghy A, Duffner ER, Levin HJ, Taylor OS, et al. Intraarterial chemotherapy for retinoblastoma in 341 consecutive eyes (1292 infusions): comparative analysis of outcomes based on patient age, race, and sex. J Aapos 2021. 2021;25:150.e1-9.

48. Abramson $\mathrm{DH}$, Shields $\mathrm{CL}$, Munier FL, Chantada GL. Treatment of retinoblastoma in 2015: Agreement and disagreement. JAMA Ophthalmol. 2015;133:1341-7.
49. Abramson DH, Shields CL, Jabbour PJ, Teixeira LF, Fonseca JRF, Marques MCP, et al. Metastatic deaths in retinoblastoma patients treated with intraarterial chemotherapy (ophthalmic artery chemosurgery) worldwide. Int J Retin Vitreous. 2017;3:40-4.

50. Yousef YA, Soliman SE, Astudillo PP, Durairaj P, Dimaras H, Chan HSL, et al. Intraarterial chemotherapy for retinoblastoma: a systematic review. JAMA Ophthalmol. 2016;134:584-91.

51. Munier FL, Gaillard M-C, Balmer A, Soliman S, Podilsky G, Moulin AP, et al. Intravitreal chemotherapy for vitreous disease in retinoblastoma revisited:from prohibition to conditional indications. Br J Ophthalmol. 2012;96:1078-83.

52. Ghassemi F, Shields CL. Intravitreal melphalan for refractory or recurrent vitreous seeding from retinoblastoma. Arch Ophthalmol. 2012;130:1268-71.

53. Shields $C L$, Douglass $A M$, Beggache $M$, Say EAT, Shields JA. Intravitreous chemotherapy for active vitreous seeding from retinoblastoma: Outcomes after 192 consecutive injections. The 2015 Howard Naquin Lecture. Retina. 2016;36:1184-90.

54. Francis J, Abramson DH, Ji X, Shields CL, Teixeira LF, Schefler AC, et al. Risk of extraocular extension in eyes with retinoblastoma receiving intravitreous chemotherapy. JAMA Ophthalmol. 2017;135:1426-9.

55. Collins ML, Bregman J, Ford JS, Shields CL. Depression, anxiety, and stress in parents of patients with retinoblastoma. AOS thesis. Am J Ophthalmol. 2019;207:130-43.

56. Parravano M, Petri D, Maurutto E, Lucenteforte $E$, Menchibni $F$, Lanzetta $P$, et al. Association between visual impairment and depression in patients attending eye clinics: a meta-analysis. JAMA Ophthalmol. 2021;139:753-61.

57. Dhingra $H$, Arya $D$, Taluja A, Das $S$, Mahajan A. A study analyzing the healthrelated quality of life of retinoblastoma survivors in India. Ind J Ophthalmol. 2021;69:1482-6.

\section{AUTHOR CONTRIBUTIONS}

CLS, ZB: Substantial contributions to the conception or design of the work; or the acquisition, analysis, or interpretation of data for the work. CS, ZB, AL, AMVS, AS, SEL, JAS: Drafting the work or revising it critically for important intellectual content. Final approval of the version to be published. Agreement to be accountable for all aspects of the work in ensuring that questions related to the accuracy or integrity of any part of the work are appropriately investigated and resolved. AL, AMVS, AS, SEL, JAS: Substantial contributions to the interpretation of data for the work.

\section{FUNDING}

Support provided in part by the Eye Tumor Research Foundation, Philadelphia, PA (CLS). The funders had no role in the design and conduct of the study, in the collection, analysis and interpretation of the data, and in the preparation, review or approval of the manuscript. CLS has had full access to all the data in the study and takes responsibility for the integrity of the data.

\section{COMPETING INTERESTS}

The authors declare no competing interests.

\section{ADDITIONAL INFORMATION}

Correspondence and requests for materials should be addressed to Carol L. Shields.

Reprints and permission information is available at http://www.nature.com/ reprints

Publisher's note Springer Nature remains neutral with regard to jurisdictional claims in published maps and institutional affiliations. 